\title{
Results Regarding the Performances of Gladiolus Hybrids Compared to Their Parents
}

\author{
Denisa Andreea HORT, Maria CANTOR*, Erzsebet BUTA, Adrian ZAHARIA \\ ${ }^{1}$ Department of Ornamental plants. University of Agricultural Sciences and Veterinary Medicine Cluj- \\ Napoca, 3-5 Mănăştur Street, Romania \\ ${ }^{*}$ Corresponding author, e-mail: marcantor@yahoo.com
}

Bulletin UASVM Horticulture 72(1) / 2015

Print ISSN 1843-5254, Electronic ISSN 1843-5394

Doi:10.15835/buasvmcn-hort:10714

\begin{abstract}
Testing the performances of hybrids compared to their parents is an important operation justified by the purpose of the breeding work. The main goal of the breeding work is to obtain bigger flowers, nicer colours, higher plants, practically, the new plant must be better than all the existing ones, but, for the landscape design this purposes may not be the same because, in the case of gladioli, we already have tall and very tall plants. Therefore, for this purpose smaller plants with different colours and compact inflorescences are needed. The experiments were conducted in 2013 in the experimental field from The Agrobotanical Garden at UASVM Cluj-Napoca. The data collected were used to calculate the hybrid vigour, the difference from the average value of parents and to the best parent in each of the six quantitative characters taken into account: plant height, flower stem length, inflorescence length, number of leaves, number of flowers in the inflorescence and flower diameter, and the results were included in the synthesis tables. The results show that two hybrid combinations are reaching reach bigger heights then their parents meaning that only one hybrid combination exceeds the height of the best parent, negative differences were registered on inflorescence length and the no. of flowers. The diameter of flowers varies between $10.1 \mathrm{~cm}(\mathrm{H} 9)$ and $16.3 \mathrm{~cm}$ (H18) registering negative differences compared to their genitors.
\end{abstract}

Keywords: differences, $F_{1}$ generation, heterosis, hybrid vigour, significance.

\section{INTRODUCTION}

In the modern era, floriculture is gaining importance as a good source of income apart from giving pleasure and happiness. In this regard, Gladiolus or sword lily (Gladiolus spp.) has gained much importance as a cut flower or for garden display (Bhajantri, 2006).

Gladiolus is widely cultivated andeconomically important flowering plants. The luxuriance unique colourful spikes of some height demanding Gladiolus cultivars have attained immense importance in the community of flower lovers (Nasir et al., 2012). The main use of gladioli for ornamental purposes is floral art; in this field they are highly appreciated. From bouquets, different arrangements to green spaces design, gladioli are found everywhere.
Landscaping design has evolved greatly from ancient to modern gardens, both in terms of surfaces, with varying sizes and plant material that is more diversified due to breeding programs.

Being a flower with a long decoration period (June to September) with normal environmental requirements (Canto ret al., 2007), it can be easily included in many garden designs. Unfortunately, in Romania, gladioli are used more as cut flowers and less in green spaces design (Horț et al., 2014).

Testing the performances of hybrids compared to their parents is an important operation justified by the purpose of the breeding work. The identification of performances of hybrids compared to their parents is useful for plants that are vegetatively propagated, without the need 
to obtain and to test the inbred lines (Muntean, 2012).

The aim of the experience was to obtain novel ornamental hybrids using the cross hybridization method.The datarecorded from thefield,measuring plants of the $F_{1}$ hybrid combinations, were used to calculate the heterosis on characters of interest in order to find which character can represent a selection character, to estimate the extent to which the production of commercial hybrids of Gladiolus hybridus can be a real solution to achieve specific breeding objectives (taller plants, longer flower stems, increasing the number of flowers in inflorescences, and the diameter of flowers, etc). But, for garden displays, are desired shorter gladioli, with a bigger number of leaves for a better coverage of the space and also with more pleinful inflorescences.

\section{MATERIALS AND METHODS}

To obtain the seven hybrid combinations, cross hybridizations were made in 2010 and 2011. On the selected parents plants were made 35 simple intraspecific-crossings. After we selected the genitors, was removed pollen from flowers of the maternal genitors. These stamens are easily pinched out with the tips of the fingers. The hand pollination was made in the morning, when the temperature reached at $23-25^{\circ} \mathrm{C}$, on the stigma of the female parent, by applying with a toothpick or finger the pollen collected a day before from the paternal male genitors. To avoid the contamination with pollen remaining from past use, the smooth brush has not been used. When the operation was finished, the pollinated plants were isolated with parchment bags or cheesecloth and labeled, to assure that some visiting insect will not accidentally mess up the cross. From five to five days from the pollination, the plans were controlled to see if the fecundation was made and to identify easily the exact moment when the first seed case cracked and the seed are obtained (Hort et al.,2012). For the experiments presented in this paperwork, the data were recorded in 2013 from the experimental field of the Floriculture department of UASVM Cluj-Napoca.

In this paper work are presented seven hybrids of Gladiolus compared with their genitors in the matter of height, stem length, inflorescence length, number of flowers and the diameter of flowers. For each one of these characters, the hybrid vigour has been calculated, using formulas presented by Ardelean, 2010, as well as the parental average and the heterosis value obtained from the difference between the value of best parent and the hybrid vigour.

\section{RESULTS}

In Table 1. are summarized results of calculation of hybrid vigour and its comparison with the average of the parents and the best parent to obtain the heterosis.

Regarding the total height of the plant, it can be noted that, from the seven studied combinations only hybrid combination $\mathrm{H} 18$ recorded positive values of hybrid vigour (12.11), the valence is

Tab 1. Hybrid vigour and heterosis value of height of plants on seven $F_{1}$ hybrids.

\begin{tabular}{|c|c|c|c|c|c|c|}
\hline Hybrid comb. & $\mathrm{P}_{1}$ & $\mathrm{P}_{2}$ & $\mathrm{~F}_{1}$ & $\begin{array}{l} \pm d \text { versus } \\
\left(\mathrm{P}_{1}+\mathrm{P}_{2}\right) / 2\end{array}$ & $\begin{array}{l} \pm d \text { versus } \\
\quad P_{\max }\end{array}$ & Hybrid vigour \\
\hline $\begin{array}{c}\text { H } 3 \\
\text { Princess M. R x Expresso }\end{array}$ & 102.67 & 110.8 & 100.03 & -6.70 & -10.77 & -6.28 \\
\hline $\begin{array}{c}\text { H6 } \\
\text { Nova Lux x Fidelio }\end{array}$ & 107.67 & 112.33 & 79.80 & -30.20 & -32.53 & -27.45 \\
\hline $\begin{array}{c}\text { H } 7 \\
\text { Nova Lux x Madonna }\end{array}$ & 107.67 & 116.90 & 99.53 & -12.75 & -17.37 & -11.35 \\
\hline $\begin{array}{c}\text { H9 } \\
\text { White Prosperity x Plumtart }\end{array}$ & 124.20 & 116.67 & 94.37 & -26.06 & -29.83 & -21.64 \\
\hline $\begin{array}{c}\text { H12 } \\
\text { Cipriana x Madonna } \\
\end{array}$ & 104.47 & 116.90 & 103.20 & -7.48 & -13.70 & -6.76 \\
\hline $\begin{array}{c}\text { H18 } \\
\text { Early Riser x Oscar }\end{array}$ & 88.67 & 106.00 & 109.13 & 11.79 & 3.13 & 12.11 \\
\hline $\begin{array}{c}\text { H19 } \\
\text { White Prosp x Praha }\end{array}$ & 124.20 & 104.57 & 102.40 & -11.98 & -21.80 & -10.47 \\
\hline
\end{tabular}


preserved both for comparison with the average of parents (11.99) and for the average height of the best parent. Therefore, we can say that at six hybrid combinations (of seven), heterosis value is negative, which means that no hybrid exceeds the height of the best parent. This result, although negative, is not necessarily a disadvantage because the breeding programme aimed to obtaining hybrids for lawns, that have low height. Therefore, in terms of the overall height of the plant, six of the seven hybrids can be recommended for design of outdoor spaces.

Floral stem length is a quantitative character particularly important both for landscape design and for increasing the quality of cut flower. For this reason, it is necessary to calculate the hybrid vigour of this character and the results obtained are condensed in Tab2.

After the calculation, the obtained values of hybrid vigour were between -12.45 and 23.98. In four hybrid combinations a positive result was obtained (H3, H7, H9, H19), and for three, the hybrid vigour was negative (H6, H12, H18). Comparing the results with the parental average, differences range between 19.79 and -11.35. Heterosis has both positive and negative values between -0.7.92 (H18) and 23.98 (H19), these values suggest that hybrids have shorter flower stems compared to the best parent.

Tab 2. Hybrid vigour and heterosis value of floral stem length on seven $\mathrm{F}_{1}$ hybrids.

\begin{tabular}{ccccccc}
\hline Hybrid comb. & $\mathrm{P}_{1}$ & $\mathrm{P}_{2}$ & $\mathrm{~F}_{1}$ & $\begin{array}{c} \pm \mathrm{d} \text { versus } \\
\left(\mathrm{P}_{1}+\mathrm{P}_{2}\right) / 2\end{array}$ & $\begin{array}{c} \pm \mathrm{d} \text { versus } \\
\mathrm{P}_{\max }\end{array}$ & Hybrid vigour \\
\hline $\begin{array}{c}\text { H 3 } \\
\text { Princess M. R x Expresso }\end{array}$ & 78.67 & 86.67 & 86.12 & 3.45 & -0.55 & 4.17 \\
\hline $\begin{array}{c}\text { H6 } \\
\text { Nova Lux x Fidelio }\end{array}$ & 84.53 & 88.2 & 79.60 & -6.76 & -8.60 & -7.83 \\
\hline $\begin{array}{c}\text { H 7 } \\
\text { Nova Lux x Madonna }\end{array}$ & 84.53 & 96.33 & 94.33 & 3.90 & -2.00 & 4.31 \\
\hline $\begin{array}{c}\text { H9 } \\
\text { White Prosperity x Plumtart }\end{array}$ & 81.4 & 89.33 & 87.04 & 1.67 & -2.29 & 1.96 \\
\hline $\begin{array}{c}\text { H12 } \\
\text { Cipriana x Madonna }\end{array}$ & 85.97 & 96.33 & 79.80 & -11.35 & -16.53 & -12.45 \\
\hline $\begin{array}{c}\text { H18 } \\
\text { Early Riser x Oscar }\end{array}$ & 75.43 & 100.2 & 80.86 & -6.95 & -19.34 & -7.92 \\
\hline $\begin{array}{c}\text { H19 } \\
\text { White Prosp x Praha }\end{array}$ & 81.40 & 83.67 & 102.33 & 19.79 & 18.66 & 23.98 \\
\hline
\end{tabular}

Tab 3. Hybrid vigour and heterosis value of inflorescence length on seven $F_{1}$ hybrids.

\begin{tabular}{ccccccc}
\hline Hybrid comb. & $\mathrm{P}_{1}$ & $\mathrm{P}_{2}$ & $\mathrm{~F}_{1}$ & $\begin{array}{c} \pm \mathrm{d} \text { versus } \\
\left(\mathrm{P}_{1}+\mathrm{P}_{2}\right) / 2\end{array}$ & $\begin{array}{c} \pm d \text { versus } \\
\mathrm{P}_{\max }\end{array}$ & Hybrid vigour \\
\hline $\begin{array}{c}\text { H 3 } \\
\text { Princess M. R x Expresso }\end{array}$ & 47.20 & 49.4 & 46.23 & -2.07 & -3.17 & -4.28 \\
\hline $\begin{array}{c}\text { H6 } \\
\text { Nova Lux x Fidelio }\end{array}$ & 47.23 & 40.77 & 43.97 & -0.03 & -3.26 & -0.06 \\
\hline $\begin{array}{c}\text { H 7 } \\
\text { Nova Lux x Madonna }\end{array}$ & 47.23 & 55.73 & 43.77 & -7.71 & -11.96 & -14.97 \\
\hline $\begin{array}{c}\text { H9 } \\
\text { White Prosperity x Plumtart }\end{array}$ & 53.73 & 48.93 & 46.56 & -4.77 & -7.17 & -9.29 \\
\hline $\begin{array}{c}\text { H12 } \\
\text { Cipriana x Madonna }\end{array}$ & 51.20 & 55.73 & 50.06 & -3.40 & -5.67 & -6.36 \\
\hline $\begin{array}{c}\text { H18 } \\
\text { Early Riser x Oscar }\end{array}$ & 43.53 & 62.67 & 53.14 & 0.04 & -9.53 & 0.07 \\
\hline $\begin{array}{c}\text { H19 } \\
\text { White Prosp x Praha }\end{array}$ & 53.73 & 52.00 & 52.7 & -0.16 & -1.03 & -0.31 \\
\hline
\end{tabular}


Positive heterosis was recorded only in hybrid H19 (18.66) which means that, only in this case, the flower stem length can be a morphological selection character for the cut flower category because, floral plants are more appreciated if their flower stems are longer.

Another character which is considered important in determining the quality of flowers is the inflorescence length. After calculating the hybrid vigour, negative values were obtained in all seven cases (Tab 3), values ranging from -14.97 and -0.06 . By comparing the hybrid vigour with the parental average, differences remain negative on six of hybrid combinations, their values falling between -4.77 (H9) and -0.03 (H6). Only a single hybrid combination (H18) has recorded a positive difference to the average of parents (0.04).

Heterosis value of the inflorescence length of the seven hybrids varies between -1.03 (H19) and -11.96 (H7), which means thatin none of the analysed hybrid combinations were obtained hybrids with flowers longer than those of the parents. Heterosis with negative values of the inflorescence length was reported by KUMAR et al. in 2008, obtained to half of the analyzed hybrid combinations. The values were recorded at nine of the 12 analyzed combinations that reached also, negative differences compared to the best parent.

In terms of 2013, the number of leaves on the analysed hybrid combinations ranged between 8.00 leaves (H18) and 9.00 leaves H9 (Tab 4). The greater hybrid vigour was obtained on H9 (11.11). At the opposite pole, H18 is the combination that has the hybrid vigor -2.61 recording an average of 0.15 lower than the parental average and 0.33 lower than the best parent. The lowest value of heterosis was obtained in combination $\mathrm{H} 18$, the difference from the value of the best parent being 0.33 . Pozitive and negative values of heterosis were reported by Kumar et al. 2007 when were identyfied 13 of 21 hybride combinations with negative values.

The number of flowers in inflorescence is particularly important in assessing the decorative value of the plant. In this case, the data presented in Tab 5 show that in the analysed combinations there was an increase in the number of flowers in inflorescence compared with the parental average or average value of the best parent.

Hybrid vigour ranges from -30.63 (H19) and -12.01 (H9), the smallest difference from parents' average being obtained in $\mathrm{H} 9(-2.03)$ but also to the parent with the highest number of flowers $(-3.17)$. As for the ornamental value, negative values of heterosis reveal that hybrid combinations did not exceeded their parents which can be an inconvenient for both the quality of cut flowers (gladioli are considered qualitative having more than 15 flowers/inflorescence) (Cantor et al., 2006) and thatof the plants used for green spaces (a richer inflorescence provides greater decorative value). However, after Hartline, 1996, the trend is to increase the range of Gladiolus having fewer flowers that could be desirable for some floral arrangements, as well for garden design, especially for rock gardens.

Tab 4. Hybrid vigour and heterosis value of number of leaves on seven $F_{1}$ hybrids.

\begin{tabular}{ccccccc}
\hline Hybrid comb. & $\mathrm{P}_{1}$ & $\mathrm{P}_{2}$ & $\mathrm{~F}_{1}$ & $\begin{array}{c} \pm \mathrm{d} \text { versus } \\
\left(\mathrm{P}_{1}+\mathrm{P}_{2}\right) / 2\end{array}$ & $\begin{array}{c} \pm \mathrm{d} \text { versus } \\
\mathrm{P}_{\max }\end{array}$ & Hybrid vigour \\
\hline $\begin{array}{c}\text { H 3 } \\
\text { Princess M. R x Expresso }\end{array}$ & 8.00 & 8.10 & 8.70 & 0.65 & 0.60 & 8.07 \\
\hline $\begin{array}{c}\text { H6 } \\
\text { Nova Lux x Fidelio }\end{array}$ & 8.10 & 8.10 & 8.20 & 0.10 & 0.10 & 1.23 \\
\hline $\begin{array}{c}\text { H 7 } \\
\text { Nova Lux x Madonna }\end{array}$ & 8.10 & 8.60 & 8.20 & -0.15 & -0.40 & -1.79 \\
\hline $\begin{array}{c}\text { H9 } \\
\text { White Prosperity x Plumtart }\end{array}$ & 8.10 & 8.10 & 9.00 & 0.90 & 0.90 & 11.11 \\
\hline $\begin{array}{c}\text { H12 } \\
\text { Cipriana x Madonna }\end{array}$ & 8.20 & 8.60 & 8.70 & 0.30 & 0.10 & 3.57 \\
\hline $\begin{array}{c}\text { H18 } \\
\text { Early Riser x Oscar }\end{array}$ & 8.10 & 8.33 & 8.00 & -0.21 & -0.33 & -2.61 \\
\hline $\begin{array}{c}\text { H19 } \\
\text { White Prosp x Praha }\end{array}$ & 8.10 & 7.87 & 8.20 & 0.21 & 0.10 & 2.69 \\
\hline
\end{tabular}


Besides the number of flowers in inflorescence, the flower size is crucial in estimating decorative value both for gladioli and for other flowering species. The data presented in Tab 6 highlights results of hybrid combinations $\mathrm{H} 3, \mathrm{H} 9, \mathrm{H} 12$ and H19 showing positive values and high hybrid vigour, confirmed by overcoming the parental average by $0.33 \mathrm{~cm}(\mathrm{H} 3), 1.35 \mathrm{~cm}$ (H9), $4.42 \mathrm{~cm}$ (H12) and $0.00 \mathrm{~cm}$ (H19). At the same time two hybrid combinations recorded positive heterosis of $1.33 \mathrm{~cm}$ and $4.24 \mathrm{~cm}$ (H9 and $\mathrm{H} 12$ ).

At the combinations that registered negative values of hybrid vigour (H6, H7, H18), can be seen that, the difference of the parental average is relatively low, ranging between -0.51 and -1.25 .
By comparison with the best parent, hybrids from combination $\mathrm{H} 12$ have the highest heterosis value of 4.24 .

\section{CONCLUSIONS}

Regarding the performances of selected hybrids it can be concluded that, better results than their parents were obtained by some hybrids on flower diameter (H3, H9 and H12); hybrid H19 registered a floral longer stem than any of his genitors.

Therefore, it can be concluded that, for the two $\mathrm{F}_{1}$ combinations ( $\mathrm{H} 9$ and $\mathrm{H} 12$ ), the breeding objective of obtaining plants with bigger flowers than those of the parents has been reached.

Tab 5. Hybrid vigour and heterosis value of number of flowers on seven $\mathrm{F}_{1}$ hybrids.

\begin{tabular}{ccccccc}
\hline Hybrid comb. & $\mathrm{P}_{1}$ & $\mathrm{P}_{2}$ & $\mathrm{~F}_{1}$ & $\begin{array}{c} \pm \mathrm{d} \text { versus } \\
\left(\mathrm{P}_{1}+\mathrm{P}_{2}\right) / 2\end{array}$ & $\begin{array}{c} \pm \mathrm{d} \text { versus } \\
\mathrm{P}_{\max }\end{array}$ & Hybrid vigour \\
\hline $\begin{array}{c}\text { H 3 } \\
\text { Princess M. R x Expresso }\end{array}$ & 15.43 & 16.33 & 13.04 & -2.84 & -3.29 & -17.88 \\
\hline $\begin{array}{c}\text { H6 } \\
\text { Nova Lux x Fidelio }\end{array}$ & 16.00 & 12.77 & 12.21 & -2.17 & -3.79 & -15.12 \\
\hline $\begin{array}{c}\text { H 7 } \\
\text { Nova Lux x Madonna }\end{array}$ & 16.00 & 18.13 & 14.06 & -3.00 & -4.07 & -17.60 \\
\hline $\begin{array}{c}\text { H9 } \\
\text { White Prosperity x Plumtart }\end{array}$ & 18.07 & 15.80 & 14.90 & -2.03 & -3.17 & -12.01 \\
\hline $\begin{array}{c}\text { H12 } \\
\text { Cipriana x Madonna }\end{array}$ & 16.00 & 18.13 & 13.98 & -3.08 & -4.15 & -18.07 \\
\hline $\begin{array}{c}\text { H18 } \\
\text { Early Riser x Oscar }\end{array}$ & 17.77 & 15.77 & 13.20 & -3.57 & -4.57 & -21.28 \\
\hline $\begin{array}{c}\text { H19 } \\
\text { White Prosp x Praha }\end{array}$ & 18.07 & 17.77 & 12.43 & -5.49 & -5.64 & -30.63 \\
\hline
\end{tabular}

Tab 6. Hybrid vigour and heterosis value of diameter of flowers on seven $F_{1}$ hybrids.

\begin{tabular}{ccccccc}
\hline Hybrid comb. & $\mathrm{P}_{1}$ & $\mathrm{P}_{2}$ & $\mathrm{~F}_{1}$ & $\begin{array}{c} \pm \mathrm{d} \text { versus } \\
\left(\mathrm{P}_{1}+\mathrm{P}_{2}\right) / 2\end{array}$ & $\begin{array}{c} \pm \mathrm{d} \text { versus } \\
\mathrm{P}_{\max }\end{array}$ & Hybrid vigour \\
\hline $\begin{array}{c}\text { H 3 } \\
\text { Princess M. R x Expresso }\end{array}$ & 7.00 & 8.73 & 8.2 & 0.33 & -0.53 & 4.25 \\
\hline $\begin{array}{c}\text { H6 } \\
\text { Nova Lux x Fidelio }\end{array}$ & 9.03 & 8.2 & 8.1 & -0.51 & -0.93 & -5.97 \\
\hline $\begin{array}{c}\text { H 7 } \\
\text { Nova Lux x Madonna }\end{array}$ & 9.03 & 8.73 & 8.4 & -0.48 & -0.63 & -5.40 \\
\hline $\begin{array}{c}\text { H9 } \\
\text { White Prosperity x Plumtart }\end{array}$ & 9.03 & 9.07 & 10.4 & 1.35 & 1.33 & 14.91 \\
\hline $\begin{array}{c}\text { H12 } \\
\text { Cipriana x Madonna }\end{array}$ & 9.10 & 8.73 & 13.34 & 4.42 & 4.24 & 49.63 \\
\hline $\begin{array}{c}\text { H18 } \\
\text { Early Riser x Oscar }\end{array}$ & 10.17 & 10.40 & 9.03 & -1.25 & -1.37 & -12.20 \\
\hline $\begin{array}{c}\text { H19 } \\
\text { White Prosp x Praha }\end{array}$ & 9.03 & 9.10 & 9.07 & 0.00 & -0.03 & 0.05 \\
\hline
\end{tabular}


Due to the fact that, $\mathrm{H} 3$ (Princess $M$. $\mathrm{R} x$ Expresso), H6 (Nova Lux x Fidelio), H7 (Nova Lux x Madonna) and H19 (White Prosp x Praha) hybrid combinations have negative values of heterosis, in the case of other combinations, the values could turned positive. However, possible negative correlation between the number of flowers and flower diameter can lead to failure of this goal, therefore, the choice of the genitors must be done judiciously.

\section{REFERENCES}

1. Ardelean M (2010). Principles of veterinary medical and agricultural research methodology, Ed. AcademicPres, Cluj-Napoca, p. 34.

2. Bhajantri A (2006). Evaluation of Gladiolus hybrids (Gladiolus hybrids hort.) for yield and quality cut flower production, PhD Diss.

3. Cantor M, Zaharia D, Pop I (2006). Studies concerning a new assortment of Gladiolus hybridusin UASVM Cluj-
Napoca collection.Scientific papers, serie Horticulture, 1(49):639-642.

4. Cantor M, Dumitraș A, Zaharia D (2007). Bulbous plants used in landscaping,Ed. Todesco, Cluj-Napoca.

5. Hartline C(1996). How to grow glorious Gladiolus, North American Gladiolus Council. p. 24.

6. Horț DA, Cantor M, Buta E, Andriescu I (2012). Researches regarding intraspecific hybridization of Gladiolus L. species in order to obtain novel ornamental varieties. Bulletin UASVM Horticulture69 (1): 172-177.

7. Horț DA, Cantor M, Buta E, Zaharia A (2014).The monitoring and evaluation of Gladiolus genitors for the Romanian breeding programme, Journal of Horticulture, Forestry and Biotechnology 18(2):57-60.

8. Kumar P, Hemanth BS, Kulkarni RC, Jagadeesha BS, Reddy AM, Shirol R, Mulge M (2008). Combining Ability and Heterosis for Growth Characters in Gladiolus (Gladiolus hybridus. Hort.). J. Agric. Sci. 21 (4):544-547.

9. Muntean L (2012). Plant breeding - general section. Ed. Risoprint, Cluj-Napoca, p.119. 